\title{
Patient-centered primary care for adults at high risk for AUDs: the Choosing Healthier Drinking Options In primary CarE (CHOICE) trial
}

Katharine A. Bradley ${ }^{1,3,4,5^{*}}$, Evette Joy Ludman ${ }^{1}$, Laura J. Chavez ${ }^{6,7}$, Jennifer F. Bobb ${ }^{1}$, Susan J. Ruedebusch ${ }^{3}$, Carol E. Achtmeyer ${ }^{9}$, Joseph O. Merrill5 ${ }^{5}$ Andrew J. Saxon ${ }^{2,8}$, Ryan M. Caldeiro' ', Diane M. Greenberg 2,8,9, Amy K. Lee ${ }^{1}$, Julie E. Richards ${ }^{1,4}$, Rachel M. Thomas ${ }^{3}$, Theresa E. Matson ${ }^{1,4}$, Emily C. Williams ${ }^{3,4}$, Eric Hawkins ${ }^{2,3,8}$, Gwen Lapham ${ }^{1}$ and Daniel R. Kivlahan²,3,8

\begin{abstract}
Background: Most patients with alcohol use disorders (AUDs) never receive alcohol treatment, and experts have recommended management of AUDs in primary care. The Choosing Healthier Drinking Options In primary CarE (CHOICE) trial was a randomized controlled effectiveness trial of a novel intervention for primary care patients at high risk for AUDs. This report describes the conceptual and scientific foundation of the CHOICE model of care, critical elements of the CHOICE trial design consistent with the Template for Intervention Description and Replication (TIDieR), results of recruitment, and baseline characteristics of the enrolled sample.

Methods: The CHOICE intervention is a multi-contact, extended counseling intervention, based on the Chronic Care Model, shared decision-making, motivational interviewing, and evidence-based options for managing AUDs, designed to be practical in primary care. Outpatients who received care at 3 Veterans Affairs primary care sites in the Pacific Northwest and reported frequent heavy drinking ( $\geq 4$ drinks/day for women; $\geq 5$ for men) were recruited (2011-2014) into a trial in which half of the participants would be offered additional alcohol-related care from a nurse. CHOICE nurses offered 12 months of patient-centered care, including proactive outreach and engagement, repeated brief motivational interventions, monitoring with and without alcohol biomarkers, medications for AUDs, and/or specialty alcohol treatment as appropriate and per patient preference. A CHOICE nurse practitioner was available to prescribe medications for AUDs.
\end{abstract}

Results: A total of 304 patients consented to participate in the CHOICE trial. Among consenting participants, 90\% were men, the mean age was 51 (range 22-75), and most met DSM-IV criteria for alcohol abuse (14\%) or dependence (59\%). Many participants also screened positive for tobacco use (44\%), depression (45\%), anxiety disorders (30-41\%) and non-tobacco drug use disorders (19\%). At baseline, participants had a median AUDIT score of 18 [Interquartile range (IQR) 14-24] and a median readiness to change drinking score of 5 (IQR 2.75-6.25) on a 1-10 Likert scale.

Conclusion: The CHOICE trial tested a patient-centered intervention for AUDs and recruited primary care patients at high risk for AUDs, with a spectrum of severity, co-morbidity, and readiness to change drinking.

Trial registration The trial is registered at clinicaltrial.gov (NCT01400581).

Keywords: Shared decision making, Alcohol use disorder, Care management, Brief interventions, Chronic Care Model, Patient-centered care, Medical management, Veterans, Primary care, Intervention

\footnotetext{
*Correspondence: Bradley.K@ghc.org

1 Kaiser Permanente Washington Health Research Institute, 1730 Minor

Ave, Suite 1600, Seattle, WA 98101-1466, USA

Full list of author information is available at the end of the article
} 


\section{Background}

Over $29 \%$ of U.S. adults have had an alcohol use disorder (AUD) at some time in their lives $[1,2]$. Most will never seek alcohol treatment, but many will receive health care in primary care settings $[1,2]$. Experts have recommended patient-centered approaches to management of AUDs in primary care for over 25 years [3-5], but remarkably little research has addressed how practically to achieve this and whether it improves patient outcomes [6-10].

In 2009, we designed the Considering Healthier drinking Options in primary CarE (CHOICE) intervention to manage AUDs as a chronic condition in primary care patients. The CHOICE model of care is a year-long intervention offered by nurses and based on (1) the Chronic Care Model, (2) principles of patient-centered care [11], and (3) promising approaches to addressing AUDs in primary care [12-23]. We hypothesized that, although most primary care patients with AUDs do not engage in alcohol treatment [2], many would be interested in addressing alcohol use as part of patient-centered care from a registered nurse. We further hypothesized that the resulting increased engagement in AUD care would lead to reductions in drinking and related symptoms, and thereby improve health outcomes. In 2010, the National Institute on Alcohol Abuse and Alcoholism (NIAAA) funded a trial to test the effectiveness of the CHOICE intervention in primary care patients at high risk for AUDs in the Veterans Affairs (VA) health care system.

This report has several purposes. First, it summarizes the conceptual and scientific foundations of the CHOICE model of patient-centered care for AUDs. Second, it describes the design of the CHOICE trial and intervention, including all elements needed for replication of the intervention and comparison to other primary care counseling interventions for AUDs, as advocated by experts $[24,25]$. Finally, it reports results of recruitment (completed October 2014) and patient-reported characteristics of the enrolled sample at baseline. Main outcomes of the CHOICE trial were under analysis at the time this report was submitted and will be reported in a follow-up paper.

\section{Conceptual and scientific foundations of the CHOICE model}

Primary care patients with AUDs fall on a spectrum from mild to severe AUDs and from low to high readiness to change. The CHOICE model of care was designed to meet the needs of these diverse patients, building on 20 years of research on patient-centered care for other chronic conditions and on specific interventions for AUDs that have been proven efficacious or shown promise in primary care patients previously, described below.

\section{The Chronic Care Model and collaborative care}

The Chronic Care Model, originally described by Wagner and Von Korff [26, 27], provides a framework for managing chronic conditions in primary care. The model, which seeks to develop informed patients who are actively involved in their own care and recognizes the central role of self-efficacy enhancement, has been proven effective in multiple trials [28].

Collaborative care is a team-based approach based on the Chronic Care Model. In collaborative care, a psychiatrist, psychologist, clinical nurse specialist, or nurse care manager offers: population-based identification, outreach and monitoring; non-judgmental and persistent attempts over time to engage patients in care; evidencebased treatments adapted to the patient's needs and goals as they change; support for patients in gaining the skills needed to manage their conditions at home and in their communities; objective measurement over time to assess whether patients have met their goals; and collaboration between the care manager and the primary care provider. Collaborative care has proven effective when care managers are located in primary care as well as when they are offsite or via telephone [29-31]. Interdisciplinary review of all patients' progress, where a collaborative care team repeatedly focuses on how to achieve symptom resolution, is a central component of collaborative care, complementing measurement-based treatment (referred to as "treat to target") [32]. Trials over the past 20 years have demonstrated the power of collaborative care to improve management and outcomes of mood disorders [33-40] and other chronic mental health and medical conditions [41].

\section{Shared decision-making}

Shared decision-making is the foundation of patient-centered care [11] and a central component of the Chronic Care Model and collaborative care [35, 42, 43]. In shared decision-making, medical providers partner with patients to support patients in making health care choices consistent with their values and priorities. Although shared decision-making is often used to support discrete choices like whether or not to have surgery, it is increasingly recognized to be relevant to chronic disease management $[44,45]$. Shared decision-making is especially important when there is no single best treatment-no treatment that is so superior and acceptable that all patients would choose it [11, 46, 47]. Shared decision-making is also critically important for treatments that require patients to be involved in treatment delivery [48]. Therefore, shared decision-making is critical for patient-centered care for patients with AUDs, a condition for which most patients do not want the standard treatment [2], the patient must carry out any care plan him or herself, and there is no 
one treatment that is generally more effective than others [49-51]. Although shared decision-making has been evaluated in patients seeking inpatient treatment for substance use disorders in Europe and resulted in increased patient autonomy and decreased drug use and psychiatric problems at 3 months $[52,53]$, it is not routinely incorporated into primary care or specialty treatment for AUDs in the U.S.

There are a number of different frameworks for offering shared decision-making $[11,46,54]$, but they all generally include three core elements [11, 46, 54]. First, providers help patients recognize that they have options and a decision to make. Second, providers present patients with information on the efficacy, advantages, and disadvantages of each option, including the option of choosing no treatment (usually combined with watchful waiting or active monitoring). Third, providers explore patients' values, goals and priorities - the guideposts for their decisions-and support them in choosing the option that is best for them at the present time [55].

Promising approaches to addressing AUDs in primary care Both chronic care management and shared decisionmaking are patient-centered approaches used to engage patients in evidence-based care. Below, we summarize evidence-based and promising approaches to managing AUDs that are practical to offer in primary care.

\section{Proactive engagement and repeated brief motivational interventions}

Almost 50 years ago, Chafetz showed that engaging patients in non-judgmental care focused on meeting their immediate needs resulted in increased engagement in alcohol treatment [56-58]. Brown showed that proactively engaging primary care patients with AUDs in 3-6 sessions of motivational telephone counseling decreased alcohol consumption at 3 months [59], while other studies have also suggested benefits of repeated brief interventions for patients with AUDs [17, 60]. Motivational Interviewing (MI) skills can be particularly helpful in increasing readiness to change as well as engagement in care for AUDs [9, 61].

\section{Repeated brief interventions with biomarker feedback}

In the first study of population-based brief interventions for heavy drinking, men with elevated serum gamma glutamyl transferase (GGT), a biomarker of hepatic injury often due to heavy drinking $[62,63]$, were monitored every 3 months for 2 years and advised to decrease drinking if their GGT was elevated [12]. The intervention was associated with decreased sick absences and hospital days and improved survival [12, 13]. Willenbring demonstrated that a similar intervention was effective in patients hospitalized for alcohol-related medical conditions who had not accepted referral to alcohol treatment. Those offered primary care to monitor their medical conditions with alcohol-related biomarkers (e.g. liver function tests) had increased abstinence, even though patients did not initially have a goal of abstinence [14, 15]. Monitoring amylase in patients with pancreatitis [22] or carbohydrate deficient transferrin (CDT) in patients with diabetes and hypertension [64] has also improved alcohol-related outcomes.

\section{Medications for AUDs can help engage patients in care and improve drinking outcomes}

Three medications for AUDs have been FDA approved (naltrexone, acamprosate and disulfiram) [23, 65, 66]. The COMBINE trial showed that naltrexone was effective with Medical Management, without specialty addictions care. Medical Management in the COMBINE trial was similar to care management of diabetes, heart failure, or depression by nurses in primary care [21]. It included review of medication adherence, side effects, and support for self-management with encouragement to attend supports for sobriety such as Alcoholics Anonymous (AA) [21]. Moreover, in COMBINE, Medical Management with placebo was more effective on some outcomes than state-of-the-art professional addictions counseling alone $[21,67]$. Therefore, primary care patients taking medications for AUDs with Medical Management might benefit from both medication and placebo effects. Recently, Oslin and colleagues showed that proactive engagement with MI skills and treatment with naltrexone increased engagement and decreased heavy drinking compared to referral to alcohol treatment for primary care patients with alcohol dependence [6].

\section{Methods}

\section{Design of the CHOICE trial}

The CHOICE intervention was designed to meet the needs of primary care patients irrespective of the severity of their AUDs or readiness to change. The intervention was tested in a randomized controlled trial from 2011 to 2015. This section describes the design of the trial, followed by a detailed description of the CHOICE intervention.

\section{Study setting}

CHOICE was conducted at three sites of the VA Puget Sound Health Care System. The VA was chosen as the setting for the trial because it conducts annual alcohol screening allowing identification of patients at increased risk of AUDs, typically under-diagnosed in medical settings [68, 69]. In addition, population-based alcohol screening in the VA would allow the CHOICE trial to 
compare patients who were enrolled into the trial, to those who were available to be screened and recruited but were not enrolled. The VA's population-based alcohol screening also allows evaluation of drinking outcomes after the formal 12 month follow-up ends. The VA also ensured access to specialty alcohol treatment for patients who were interested.

\section{Eligibility criteria}

Primary care patients from the three study sites were eligible if they were $21-75$ years old and at high risk for AUDs based on self-report of frequent heavy drinking on a telephone screen. Table 1 lists inclusion and exclusion criteria. Patients less than 21 are rarely seen in the VA, and patients over 75 years were excluded due to limited information on the safety of AUD medications in the elderly. Patients who reported 4 or more drinks in a day for women and 5 or more drinks for men [70] at least twice weekly, or once a week for patients with prior alcohol treatment [71], were eligible (Table 1). Although the intervention was designed for patients with AUDs, many patients with AUDs might under-report symptoms (especially those not interested in changing); therefore, having a DSM-IV AUD diagnosis was not an eligibility criterion. Exclusions were limited to recent engagement in alcohol treatment (past 90 days), so as not to interfere with ongoing care, those required for safety (e.g. pregnancy), and those that would decrease likelihood that participants would be lost to follow-up (Table 1).

\section{CHOICE trial recruitment procedures}

CHOICE recruitment required a number of steps to protect privacy and safety (Fig. 1).

Pre-screening Review of the electronic health record (EHR) identified patients eligible for screening and possible recruitment because they received primary care at one of the three study sites and had screened positive for unhealthy alcohol use on the AUDIT- $C$ at $\geq 4$ points for women and $\geq 5$ points for men [72]. In addition, providers were allowed to refer patients to the study, and flyers were posted to allow patients to self-refer. Before being sent an invitation letter for CHOICE study screening, patients identified from the EHR were reviewed for appropriateness for the trial by their primary care providers, followed by manual EHR review by study staff for exclusions (Table 1).

The CHOICE trial included a randomly selected "No Contact Control Group" to allow evaluation of the possible effects of recruitment and assessment alone (assessment reactivity) [73-77]. About $25 \%$ of men who were otherwise eligible for recruitment based on EHR prescreening were never contacted by the study. Women were not included in the No Contact Control Group

Table 1 Inclusion and exclusion criteria for the CHOICE trial

\begin{tabular}{|c|c|c|c|c|c|}
\hline & \multicolumn{5}{|c|}{ Assessed via... } \\
\hline & EHR & $\begin{array}{l}\text { Primary care } \\
\text { provider review }\end{array}$ & $\begin{array}{l}\text { Manual } \\
\text { EHR review }\end{array}$ & $\begin{array}{l}\text { Telephone } \\
\text { screen }\end{array}$ & $\begin{array}{l}\text { Baseline } \\
\text { in-person visit }\end{array}$ \\
\hline \multicolumn{6}{|l|}{ Inclusion criteria } \\
\hline Receiving primary care in study clinic & $x$ & & $x$ & $x^{a}$ & $X^{a}$ \\
\hline Age $21-75$ years & $x$ & & $x$ & $x^{a}$ & $x^{a}$ \\
\hline Frequent heavy drinking ${ }^{b}$ & & & & $x$ & $x$ \\
\hline \multicolumn{6}{|l|}{ Exclusion criteria } \\
\hline Medically or psychiatrically unstable & & $x$ & $x$ & & $x$ \\
\hline Cognitive impairment & & $x$ & $x$ & $x$ & $x$ \\
\hline Less than 1 year life expectancy & & $x$ & $x$ & & \\
\hline Alcohol treatment in past 90 days & $x$ & & $x$ & $x$ & $x$ \\
\hline Current pregnancy or planned next year & & & $x$ & $x$ & $x$ \\
\hline Enrolled in current VA trial & & & $x$ & & \\
\hline Behavioral warning flag in EHR & $x$ & & $x$ & & \\
\hline Leaving VA facility in next year & & & & $x$ & $x$ \\
\hline VA employee & $x$ & & $x$ & $x^{a}$ & $x^{a}$ \\
\hline Excluded by primary care provider & & $x$ & & & \\
\hline No valid phone or address & $x$ & & $x$ & & \\
\hline
\end{tabular}

a Only for self-referred patients

${ }^{b}$ Self report of 4 or more drinks (women) and 5 or more (men) at least twice a week, or at least once a week for patients who reported previous alcohol treatment 


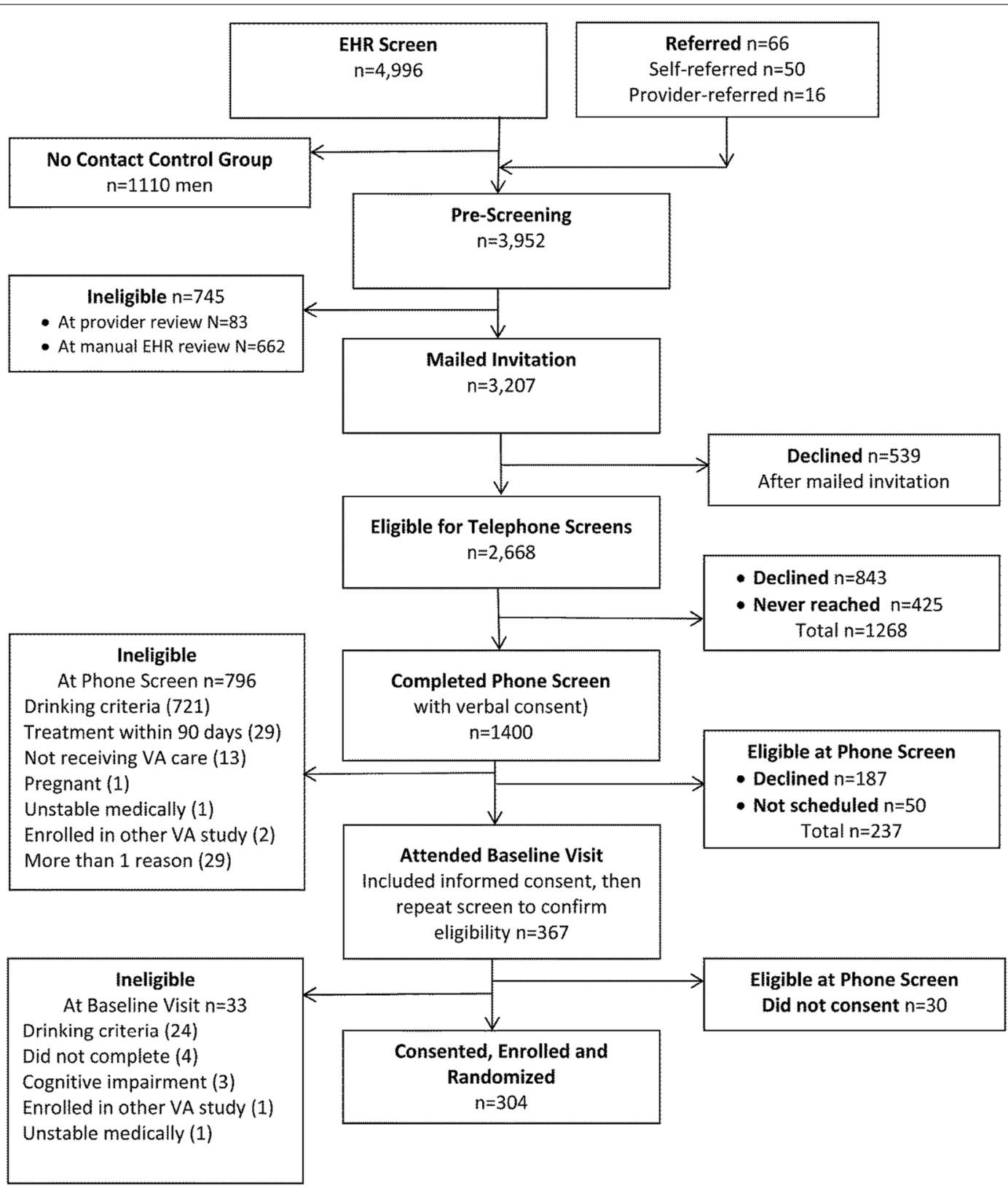

Fig. 1 Patients identified for recruitment from the EHR: ineligible, declining, never reached, and enrolled

to maximize the number of women in the trial because women make up less than $10 \%$ of VA patients.

Mailed invitation Patients were sent a letter inviting them to be screened for a study testing "a program designed to improve the health of Veterans who drink alcohol" (Additional file 1: A-Recruitment Materials). The invitation was either signed by their primary care provider or the principal investigator if providers preferred. The letter included a $\$ 2$ pre-incentive [78-80] and allowed patients to opt out of being called for study screening by returning a post card or calling a toll free number.

Telephone screening Study coordinators telephoned patients for screening and possible recruitment (after verbal consent), if patients had not declined after mailed invitations. Women were preferentially screened in order to maximize their recruitment. Eligible patients, based on the telephone screen [81-85], were invited to schedule an 
in-person visit with an enrollment coordinator to determine interest in participating, obtain written informed consent, determine final eligibility, and administer baseline assessments (Additional file 1: A-Recruitment Materials).

Baseline enrollment visit Three enrollment coordinators conducted baseline assessments. At the baseline visit, informed consent was obtained and patient eligibility was established including repeat assessment of drinking eli- gibility criteria and cognitive assessment with the MiniCog (Table 1; Additional file 1: A-Recruitment Materials) [81-85]. Eligible participants completed all baseline assessments in person (Table 2), including laboratory tests, and self-administered screens for unhealthy alcohol use (past year), depression (past 2 weeks), and past month posttraumatic stress disorder (PTSD), using the Alcohol Use Disorders Identification Test (AUDIT) [86], the 9-item Patient Health Questionnaire (PHQ-9) [87], questions about experiences of trauma [88], and the PTSD

Table 2 Assessments and laboratory tests at baseline, 3 and 12 months

\begin{tabular}{|c|c|c|c|c|}
\hline & Timeframe & Baseline & 3 months & 12 months \\
\hline \multicolumn{5}{|l|}{ Telephone screen } \\
\hline Number of heavy drinking days in the past 28 days & Past 28 days & $x^{a}$ & & \\
\hline Prior treatment & $L T, P 90 D$ & $x^{a}$ & & \\
\hline \multicolumn{5}{|l|}{ Self-administered surveys } \\
\hline Alcohol Use Disorder Identification Test (AUDIT) [86] & PY & $x^{a}$ & & $x$ \\
\hline AUDIT consumption questions (AUDIT-C) & Past 4 weeks & & & $x$ \\
\hline 9-item Patient Health Questionnaire (PHQ-9) [87] & Past 2 weeks & $x^{a}$ & & $x$ \\
\hline Traumatic experience ever (MINI) [88] & $\mathrm{LT}, \mathrm{PM}$ & $x^{a}$ & & \\
\hline PTSD Check List (PCL) [89] & PM & $x^{a}$ & & \\
\hline \multicolumn{5}{|l|}{ Interview } \\
\hline Mini-Cog [81-83] & Current & $x$ & & \\
\hline Health habits & PM, current & $x$ & $x$ & $x$ \\
\hline 12-item Short Form (SF-12) Veterans Version $[134,135]$, & PM & $x$ & $x$ & $x$ \\
\hline 28 day Time Line Follow Back Interview, alcohol [90] & Past 28 days & $x$ & $x$ & $x$ \\
\hline Short Inventory of Problems (SIP) [91, 92] & $\mathrm{LT}, \mathrm{P} 3 \mathrm{Mo}$ & $x$ & $x$ & $x$ \\
\hline DSM-IV Major Depressive (current, past) (MINI) [88] & $\mathrm{LT}, \mathrm{P} 2 \mathrm{~W}$ & $x^{a}$ & & \\
\hline DSM-IV Panic disorder (current, lifetime) (MINI) [88] & $\mathrm{LT}, \mathrm{PM}$ & $x^{a}$ & & \\
\hline Generalized Anxiety Disorder Screen (GAD-7) [115] & $\mathrm{P} 2 \mathrm{~W}$ & $x^{a}$ & & \\
\hline DSM-IV AUD (MINI) [88] & PY & $x^{a}$ & & $x$ \\
\hline Craving question [116] for DSM-5 AUD $[136,137]$ & LT & $x^{a}$ & & $x$ \\
\hline DSM-IV DUD (MINI) [88] & LT, PY & $x^{a}$ & & \\
\hline DUD craving question & LT & $x^{a}$ & & \\
\hline Importance, readiness, confidence rulers $[138,139]$ & None & $x$ & $x$ & $x$ \\
\hline Important People Inventory [140] & P4Mo & $x$ & & \\
\hline Socio-demographics & Current & $x$ & & $x$ \\
\hline Family history AUDs (parents, sibling children) & LT & $x$ & & \\
\hline Alcohol treatment or related services (e.g. AA) [1] & $\mathrm{LT}, \mathrm{P} 3 \mathrm{Mo}, \mathrm{PY}$ & $x$ & & $x$ \\
\hline AA meetings [141] & LT, PY & & & $x$ \\
\hline Distance to appointments & None & $x$ & & \\
\hline Non-VA emergency department visits & P3Mo, PY & $x$ & $x$ & $x$ \\
\hline Non-VA hospitalizations & P3Mo, PY & $x$ & $x$ & $x$ \\
\hline Other non-VA care & P3Mo, PY & $x$ & $x$ & $x$ \\
\hline \multicolumn{5}{|l|}{ Laboratory tests } \\
\hline Gamma glutamyl transferase (GGT) [117] & None & $x^{a}$ & & $x$ \\
\hline Carbohydrate deficient transferrin (CDT) [117] & None & $x^{a}$ & & $x$ \\
\hline Mean corpuscular (MCV) [117] & None & $x^{a}$ & & $x$ \\
\hline
\end{tabular}

a Available to CHOICE RNs at Baseline; PM past month, LT lifetime, $P Y$ past year, $P 90 D$ past 90 days, $P 3 M o$ past 3 months, $P 4 M 0$ past 4 months, $P 2 W$ past 2 weeks 
Checklist (PCL) [89], respectively. Alcohol and drug use disorders in the past year were assessed with the Mini International Neuropsychiatric Interview (MINI). Alcohol consumption was assessed with a 28-day time-line follow-back (TLFB) [90], and alcohol-related problems ever and in the past 3 months were assessed with the Short Inventory of Problems (SIP) [91, 92]. Patients were compensated $\$ 10$ for rescreening at baseline and another $\$ 10$ for the baseline assessment, which lasted $\sim 1 \mathrm{~h}$.

\section{Randomization}

After baseline assessments, participants were randomized $(1: 1)$ to either the CHOICE Intervention or Usual Care control. Randomization was stratified on sex, DSM-IV alcohol dependence (yes/no), and site $(\mathrm{n}=3$ ) in permuted blocks of varying size. Randomization was conducted using computer-generated random numbers, and allocation was concealed by computer software.

\section{Usual alcohol-related care in the study primary care clinics}

Prior to the start of the CHOICE trial, all study sites had implemented annual alcohol screening and a single brief intervention for those who screened positive at AUDITC scores $\geq 5$ points, as well as integrated mental health care, as part of a national requirement [93-96]. At VA Puget Sound, this included use of collaborative care for depression, but not AUDs, as well as co-located psychiatrists and psychologists. Beginning in 2010, the study sites also implemented patient-centered medical homes, referred to as Patient Aligned Care Teams (PACTs) in the VA. The PACTs had increased resources for nurse care management [97] but did not provide care management for AUDs. As a result, the standard management of AUDs in primary care was still referral to specialty addiction treatment during this trial.

\section{Data collection}

The CHOICE trial measured patient-reported outcomes, laboratory biomarkers, and VA and non-VA health care utilization (including care by the CHOICE team) at 3 and 12 months (Table 2). Main outcome measures at 12 months-percent heavy drinking days in the past 28 days [98] and a "good drinking outcome" (drinking below NIAAA recommended limits in the past 28 days without alcohol-related symptoms in the past 3 months on the SIP) $[21,99]$ - were collected by the Kaiser Permanente Washington Health Research Institute Survey Research Department (an independent survey team) using computer assisted telephone interviews with interviewers blinded to treatment assignment. Telephone interviews were used to provide more flexibility than inperson interviews. Computers, tablets, or smartphones were not used because many patients did not own them when the study was designed (2009-2010), and using a common mode of assessment was preferred.

At 12 months, 4 study coordinators arranged for participants to complete additional self-report questionnaires (e.g. AUDIT and PHQ-9) and laboratory tests. However, study coordinators could not be reliably blinded to treatment assignment due to their interactions with patients.

\section{The CHOICE intervention}

The 12-month CHOICE intervention consisted of chronic care management provided by one of two registered nurses ("CHOICE nurses") and supervised by an interdisciplinary team ("CHOICE team"). A decision was made not to ask participants' primary care providers to prescribe AUD medications-unlike collaborative care for depression-after initial discussions with primary care clinicians indicated many would not want to prescribe AUD medications. A CHOICE nurse practitioner, a VA primary care provider, was available to prescribe and manage medications for AUDs. The CHOICE nurses had prior research experience as care managers for diabetes, heart failure, and/or depression [100, 101]. However, neither the nurses nor the nurse practitioner had prior experience managing AUDs or medications for AUDs.

CHOICE nurse and nurse practitioner training The first nurse and nurse practitioner were initially given articles and protocols to read $[14,21,33,36,43,65,102-108]$, then received $16 \mathrm{~h}$ of training, which included motivational interviewing (MI) skills focused on engagement, ways to increase the importance patients placed on changing their drinking, and building patient self-efficacy. An additional $2 \mathrm{~h}$ of training addressed medications and laboratory monitoring $[21,65]$. The second nurse was added to the study after the caseload of the first increased. The second nurse had experience with MI skills from working in a prior trial [100] and required fewer hours of training (6 total). Nurses participated in a site visit to the VA specialty addiction treatment program, which they found invaluable for informing patients about available services.

Proactive telephone outreach A nurse telephoned each intervention group patient as soon as possible after randomization to invite him/her to an initial visit ("engagement visit") [109]. As above, patients had been told that randomly selected patients would be offered services, but they were not required to accept them, making CHOICE an "encouragement trial" [110-113]. Nurses made every effort to schedule the initial engagement visit in person. At two of the three sites, nurse office visits were not in the primary care clinics due to space constraints and were instead in research offices nearby at the same site. 
Review of the medical record and baseline assessments Prior to the engagement visit, nurses reviewed patients' EHRs for all medical and mental health conditions potentially impacted by alcohol use and any alcohol treatment history. They also reviewed screens and brief instruments administered during the CHOICE baseline assessment (Table 2) [86-89, 114-116] and alcohol biomarker results: GGT, CDT, and red cell mean corpuscular volume (MCV) [117, 118].

Patient engagement The goal of the engagement visit was to get to know the patient-his/her goals, values, and life priorities - and to engage the patient in a caring, non-judgmental relationship that could support him/her in making changes [119]. The CHOICE nurses learned about relationships and activities important to the patient and how those activities related to the patient's drinking. Engagement visits typically lasted $\sim 60-90 \mathrm{~min}$, and, if more time was needed, engagement was sometimes spread over two encounters. The nurse used a template to document the engagement visit in the EHR, with the primary care provider copied on the note, which was also provided to the CHOICE team (Additional file 1: B-Fictional Example of Template for EHR Engagement Note).

Repeated brief interventions using MI skills and shared decision-making After engagement, usually at the second visit, CHOICE nurses provided feedback from patients' baseline assessments. Abnormal lab tests and medication options for AUDs were reviewed irrespective of whether or not patients met criteria for DSM-IV AUDs on the CHOICE baseline assessment in an effort to link drinking and health and decrease stigma. Per patient interest, nurses also provided handouts about the medical effects of drinking (such as calories from alcohol, a topic of interest to many patients) to enhance motivation for change $[108,120]$. At the same time, nurses made it clear to patients that any decision to change their drinking was up to them and that the nurse would continue to support them irrespective of their individual goal or readiness to change. Patients who were not interested in changing were invited to consider self-monitoring (documenting their drinking daily in a manner convenient to them). Patients interested in making changes were supported in considering whether they wanted to cut down or stop drinking. Information was also provided on the range of treatment options that could support patients in making changes in their drinking, including biomarker monitoring and feedback, CHOICE nurse visits, AUD medication, specialty alcohol treatment, and AA, or other mutual help.

Ongoing patient support and proactive monitoring Over the 12 month intervention, nurses continued to offer ongo- ing support, monitoring, MI, and shared decision-making if patients were interested in considering change(s). Follow-up visits were in person or via telephone, depending on patient preference, and lasted from 5 to $60 \mathrm{~min}$, depending on patient needs and preference. Nurses and patients collaboratively determined visit frequency; generally visits tapered from weekly to monthly. Nurses called patients who missed appointments and continued followup with patients even if patients did not respond, leaving voice messages or sending letters at least once a month (unless patients requested otherwise). The content of follow-up visits varied depending on patients' needs, but visits always included efforts to build motivation and selfefficacy. Patients' progress was monitored in several ways during these visits per patient preference: self-monitoring with a diary or other calendar, use of laboratory biomarkers, and/or the AUDIT. At each visit, nurses and patients also assessed progress on their goal(s), problem-solved challenges to goal attainment, and considered additional treatment services as appropriate. Nurses helped coordinate access to the patient's chosen treatment, including inpatient alcohol withdrawal, if necessary.

Weekly CHOICE team meetings The CHOICE nurses, nurse practitioner, and interdisciplinary $\mathrm{CHOICE}$ teamincluding 2 psychologists, 2 addiction psychiatrists, and 2 primary care internists-met weekly. These meetings were a critical part of the intervention, lasted an hour, and were held in person with the nurses and 3 members of the interdisciplinary team, while the other 3 members were usually on the phone. The CHOICE team was large to allow adequate coverage for weekly meetings for 3.5 years. Team meetings used a roster of intervention patients (Additional file 1: C-Fictional CHOICE Patient Roster) that included: age, sex, randomization date, number of visits to date, last visit, last 2 values for each laboratory biomarker (CDT, MCV, GGT), most recent AUDIT and PHQ-9 scores, last AUD medication and date, and comments (e.g. enrolled in treatment). Each week, nurses presented new patients and took turns reviewing their entire roster, discussing about 25-30 patients in an hour with a focus on those patients who were not engaged or not making progress. The CHOICE nurse practitioner also consulted about medications during CHOICE team meetings. In addition to the larger CHOICE team meeting, the nurses also met with one psychologist and internist for an hour most weeks to discuss new and challenging patients and to review MI skills. Discussions with both the large and small groups were patient-focused and aimed to support the nurses in developing persistent caring relationships and adapting care when patients did not respond. There was no systematic fidelity monitoring of nurse adherence to the treatment model. 
Communication with primary care providers and other $V A$ providers The CHOICE intervention did not require VA primary care providers to be actively involved in their patients' alcohol-related care (Fig. 2). However, nurses documented all visits in the EHR and communicated with the primary care provider via notes in the EHR by copying the primary care provider or asking them to co-sign the note when medically relevant information was provided (e.g. a need for depression treatment, medically-managed alcohol withdrawal, or plans for AUD medications).

\section{Results}

\section{Recruitment and characteristics of CHOICE participants Screening and recruitment}

Figure 1 depicts the recruited patient sample and numbers of patients who were: found ineligible; not willing to be screened or participate; never reached; or eventually enrolled. EHR screening initially identified 4996 primary care patients between the ages of 21 and 75 who screened positive for unhealthy alcohol use. After 1110 men were randomized to the No Contact Control Group, and primary care providers referred another 16 patients, and 50 patients self-referred, a total of 3952 were available for screening and recruitment (3429 men and 523 women). A total of 1574 were found ineligible based on provider review (83), manual chart review (662), telephone screening (796), or baseline interviews (33). Of the remaining 2378 patients not known to be ineligible, 425 (18\%) were never reached for telephone screening, 1649 (69\%) declined to participate, and 304 (13\%) were enrolled in the trial. Of the 1649 patients who declined to participate, 1382 (84\%) did so before eligibility was determined (539 after mailed invitations and 843 when initially reached

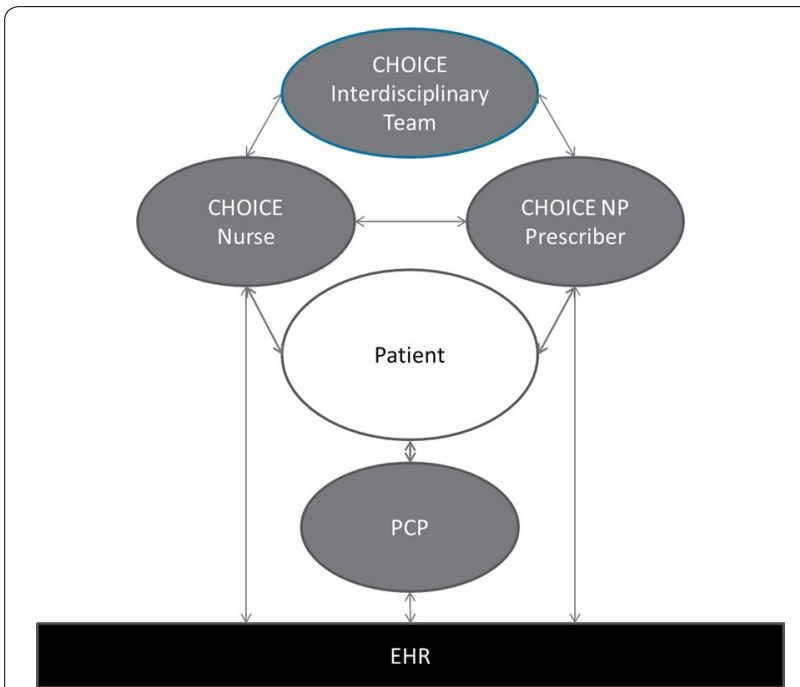

Fig. 2 Diagram of the CHOICE intervention team. EHR electronic health record; $P C P$ primary care provider for telephone screening); only 267 (16\%) declined participation after they were preliminarily deemed eligible based on telephone screening (187 explicitly declining participation after screening, 50 never scheduling, and 30 not consenting after coming for in-person visits).

Of 1400 patients who completed telephone screens, 829 (59\%) were found ineligible at telephone screening (796), or at baseline in-person assessments (33). As shown in Fig. 1, most ineligible patients were ineligible because they did not drink at levels required by the study (87\%). Of the remaining 571 patients who were potentially eligible based on phone screens, $47 \%$ declined (Fig. 1), and a total of 304 patients (53\%) enrolled in the trial, including 275 men $(90.5 \%)$ and 29 women $(9.5 \%)$.

\section{Differences between enrolled and non-enrolled patients}

Age, gender, and AUDIT-C scores from the VA's EHR were used to compare the 304 patients enrolled in the CHOICE trial to: (1) the 2074 patients who declined to participate (1649) or were never reached (425); and (2) the 1574 patients found ineligible at screening. Compared to the 2074 patients who declined to participate or were never reached, the 304 patients who enrolled in the trial were of similar age (mean age 51.4 years enrolled vs. 51.0 years declined/not reached; Wilcoxon ranked sum test $p=0.89$ ) and gender $(90.5 \%$ male in the enrolled sample vs. $87.8 \%$ in the declined/not reached sample; Fisher exact test $p=0.19$ ). However, enrolled patients had higher mean AUDIT-C scores (7.0 points in the enrolled sample vs. 6.4 points in the declined/not reached sample; $p<0.0001$ ). The difference in AUDIT-C scores was statistically significant for both men $(7.2$ vs $6.6 ; p<0.0001)$ and women (5.5 vs $4.8 ; p$ 0.035). Compared to the 1574 patients determined ineligible, the 304 patients who enrolled in the trial were older (51.4 vs 47.8 years; $p=0.0003$ ) with age differences among men ( 52.2 vs $48.7 ; p=0.001$ ) but not women (43.7 vs $42.8 ; p=0.68$ ), and enrolled patients were more likely to be male ( 90.5 vs $84.8 \% ; p=0.009$ ) and had higher AUDIT-C scores (7.0 vs 6.4; $p<0.0001$ ), using the same approaches for statistical testing as for above comparisons to the 2070 declined/not reached. Because, some referred patients lacked these EHR measures, especially AUDIT-C screens-missing for up to 20 of enrolled, 14 of declined/ not reached, and 32 of ineligible patients-analyses were repeated excluding referred patients, and results were not meaningfully changed (Additional file 1: Characteristics of Patients Enrolled, Ineligible and Declined/Not Reached).

\section{Enrolled sample}

The 304 patients who enrolled in the trial were predominantly white, with ages ranging from 22 to 75 years (mean 51.4); 81.3\% were married at some time in their lives (Table 3). Tobacco smoking (44.1\%), depression 
Table 3 Baseline characteristics of study sample $(\mathbf{N}=\mathbf{3 0 4})$

\begin{tabular}{|c|c|c|}
\hline & $\mathbf{N}$ & $\%$ \\
\hline Men & 275 & $(90.5)$ \\
\hline \multicolumn{3}{|l|}{ Age (years) } \\
\hline $21-35$ & 54 & $(17.8)$ \\
\hline $35-49$ & 65 & (21.4) \\
\hline $50-64$ & 131 & $(43.1)$ \\
\hline $65-75$ & 54 & $(17.8)$ \\
\hline \multicolumn{3}{|l|}{ Race/ethnicity } \\
\hline Black & 39 & (12.8) \\
\hline White & 206 & (67.8) \\
\hline Native American & 25 & $(8.2)$ \\
\hline Native Hawaiian/PI & 5 & (1.6) \\
\hline Bi/multiracial & 22 & $(7.2)$ \\
\hline Asian & 2 & $(0.7)$ \\
\hline Other & 5 & (1.6) \\
\hline Hispanic & 21 & (6.9) \\
\hline \multicolumn{3}{|l|}{ Marital status ${ }^{\mathrm{a}}$} \\
\hline Never married & 56 & (18.4) \\
\hline Married/partnered & 136 & $(44.7)$ \\
\hline Separated & 13 & $(4.3)$ \\
\hline Divorced & 91 & (29.9) \\
\hline Widowed & 7 & $(2.3)$ \\
\hline \multicolumn{3}{|l|}{ Education } \\
\hline High school/GED or less & 65 & (21.4) \\
\hline Some college/tech school & 170 & (55.9) \\
\hline College or post graduate & 69 & (22.7) \\
\hline \multicolumn{3}{|l|}{ Income $e^{\mathrm{a}}$} \\
\hline$<\$ 15,000$ & 49 & $(16.1)$ \\
\hline$\$ 15,000-29,999$ & 62 & (20.4) \\
\hline$\$ 30,000-59,999$ & 96 & (31.6) \\
\hline$\$ 60,000-89,999$ & 57 & $(18.8)$ \\
\hline$\geq \$ 90,000$ & 38 & $(12.5)$ \\
\hline \multicolumn{3}{|l|}{ Behavioral health screening } \\
\hline Smokes tobacco (some/daily) & 134 & $(44.1)$ \\
\hline Depression (PHQ-9 $\geq 10$ points) & 138 & $(45.4)$ \\
\hline Suicidal thoughts > half days (PHQ-9) & 16 & (5.3) \\
\hline GAD (GAD-7 $\geq 10$ points) & 92 & (30.3) \\
\hline DSM-IV PTSD based on PCL ${ }^{a}$ & 125 & $(41.2)^{\mathrm{a}}$ \\
\hline DSM-IV Non tobacco, DUD, past year (MINI) & 57 & $(18.8)$ \\
\hline \multicolumn{3}{|l|}{ Alcohol use, problems and history } \\
\hline Drinks $\geq 6$ drinks daily (AUDIT Q\#3) & 155 & $(51.0)$ \\
\hline AUDIT score $\geq 20$ & 134 & $(44.1)$ \\
\hline DSM-IV AUD, past year (MINI) & 223 & (73.4) \\
\hline DSM-IV alcohol dependence, past year (MINI) & 180 & $(59.2)$ \\
\hline Prior alcohol treatment or related services & 169 & (55.6) \\
\hline \multicolumn{3}{|l|}{ Patient reported importance of change } \\
\hline Not important & 87 & (28.6) \\
\hline Somewhat important & 110 & $(36.2)$ \\
\hline Very important & 107 & $(35.2)$ \\
\hline
\end{tabular}

Table 3 continued

\begin{tabular}{lcc}
\hline & N & $\%$ \\
\hline Patient reported confidence in ability to change & 58 & $(19.1)$ \\
Not confident & 112 & $(36.8)$ \\
Somewhat confident & 134 & $(44.1)$ \\
Very confident & & \\
Patient reported readiness to change & 98 & $(32.2)$ \\
Not ready & 130 & $(42.8)$ \\
Somewhat ready & 76 & $(25.0)$ \\
Ready & \multicolumn{3}{c}{ a 4 missing }
\end{tabular}

(45.4\%), anxiety (30.3\%), and PTSD (41.2\%) were relatively common in the 304 participants in the trial, and almost 1 in 5 met criteria for non-tobacco, non-alcohol DSM-IV drug use disorders (DUDs; 18.8\%). Participants reflected a spectrum of unhealthy alcohol use with a median full AUDIT score of 18 [interquartile range (IQR) $14-24]$, and 51\% reported drinking 6 or more drinks daily or almost daily on the AUDIT (Table 3). At baseline, the median percent days of heavy drinking was $64 \%$ (IQR 35-93\%), and the median past 3 month SIP score was 7 (IQR 2-13). Overall, 73.4\% of participants met DSM-IV criteria for past year AUD (59.2\% for dependence alone) based on the MINI, and over half reported having "gone anywhere or seen anyone for a reason related in any way to your drinking (physician, counselor, AA, other community agency or profession)" [1]. Although 71.4\% reported that it was "somewhat" to "very" important to change their drinking, only $44.1 \%$ were very confident they could change. The self-reported readiness to change drinking at baseline varied (Table 3), with a median readiness score of 5 (IQR 2.75-6.25) on a 10-point Likert scale.

\section{Discussion}

The purpose of this report was to provide a rationale and description of the CHOICE intervention and trial as recommended by experts [24]. The CHOICE intervention was designed to improve outcomes of primary care patients at high risk for AUDs by offering patientcentered chronic care management using MI skills and shared decision-making over 12 months. Patients were recruited and engaged in the intervention regardless of their recognition of problems due to drinking, severity of unhealthy alcohol use, or readiness to change drinking. The CHOICE trial will evaluate the effectiveness of the nurse care management intervention for resolving high risk drinking and alcohol-related symptoms. Baseline data show that the trial recruited a sample of patients 
with varying severity of unhealthy alcohol use, readiness to change, and a significant burden of mental health and other substance use conditions.

Randomized controlled trials of interventions to manage AUDs in primary care patients have had varying designs and results $[6,7,9,14,59]$. Understanding the implications of their varying results requires a detailed knowledge of the interventions, populations studied, and trial designs. Unfortunately, all too often, neither is adequately characterized in relatively brief reports in medical journals [24]. As a result, experts have recommended several frameworks to improve reporting and interpretation of the literature on behavioral interventions that can be offered in primary care $[24,25,121,122]$. One recommendation is that a checklist, the Template for Intervention Description and Replication (TIDieR), be used to ensure adequate description of behavioral interventions and the design of trials conducted in primary care [25]. This report includes those TIDieR elements-intervention components, materials used in the intervention, procedures and processes used, intervention providers and their expertise, modes of delivery, locations, whether the intervention was personalized or adapted, and how adherence was assessed-that are known before blinded analyses of main and secondary outcomes are completed.

Randomized controlled trials of behavioral interventions in primary care samples fall on a continuum from purely "explanatory," efficacy trials to more "pragmatic" effectiveness trials, and different dimensions of a trial can vary in the extent to which they are explanatory or pragmatic [123]. The CHOICE trial is considered a blended pragmatic effectiveness-efficacy trial based on the 10 indicators of the "Pragmatic-Explanatory Continuum Indicator Summary (PRECIS) [123]. Pragmatic elements of the CHOICE trial include: non-stringent criteria for inclusion/exclusion, the intervention which was flexible and not monitored systematically for fidelity, and use of telephone interviews for outcomes, all designed to maximize flexibility and thereby external validity. Exclusion criteria were limited, and the primary inclusion criterion relied on the frequency of heavy drinking. Frequent heavy drinking was used as an inclusion criterion because it is strongly associated with AUDs [70, 124] commonly assessed by brief alcohol screens in primary care [125], and because AUDs are often under-recognized in primary care [69], and patients under-report AUD symptoms due to stigma [126]. Consistent with shared decision-making principles, the CHOICE intervention was adapted to patient preferences regarding drinking goals, frequency of contacts, setting (telephone vs in person), and treatment options. The comparison condition was usual primary care with no additions. Measurements were pragmatic in that main outcomes were measured by telephone at diverse times of day, seven days a week, to increase flexibility and acceptability to patients. Only limited secondary outcomes were collected from patients at three months, with EHR data used to measure other secondary outcomes to decrease participant burden and assessment reactivity. Finally, embedding the trial in the VA health care system enabled future use of annual alcohol screening and the EHR to evaluate longer term outcomes after the main patient reported outcomes at 12 months. While these pragmatic elements of the trial were expected to limit its explanatory potential, especially if the intervention was not effective, explanatory elements below were designed to counter those limitations.

Despite the above pragmatic elements of the CHOICE trial design, other elements were less pragmatic. The recruitment procedures included at least seven interactions between research staff and all patients (including the control group) before the 12 month assessment: an invitation letter; a telephone screen; an appointment reminder letter with consent form; an in-person baseline assessment; a letter with results of randomization; a 3-month reminder letter; and a telephone assessment at 3 months, with each contact often requiring many attempts to reach or schedule the patient. These could act as a barrier to participation, but also as a catalyst to change by increasing self-awareness of alcohol-related problems in both groups [76, 77, 122, 127]. The 13-page written informed consent document, patient-level randomization, and measurement of main outcomes with patient interviews were also on the explanatory end of the continuum. The randomly selected No Contact Control Group of men will allow evaluation of the potential impact of recruitment and assessment at baseline and three months, allowing explanatory analyses of changes in drinking in the usual care group-albeit with pragmatic measures. Elements of the intervention, which were also less pragmatic, included having CHOICE nurses manage only AUDs while referring other medical or mental health issues to primary care teams, not requiring that primary care providers provide any of the alcohol-related care including prescription of AUD medications, location of the nurses outside primary care clinics, and collaboration between CHOICE RNs and primary care providers limited largely to medications or medical issues.

The CHOICE trial included 304 primary care patients, a low proportion of those who were initially identified from the EHR for screening and recruitment for the trial. Of the 3952 patients initially identified, 1807 (46\%) either declined before eligibility was determined (1382) or were never reached (425). Of the 571 patients potentially eligible based on phone screening for the trial, $53 \%$ enrolled. 
Most patients who were ineligible did not drink above levels required for inclusion. Given all the demands of screening, recruitment, and measurement above, the low enrollment rate among all VA patients eligible for screening and recruitment was as expected and similar to the proportion of patients who engaged in prior effectiveness-efficacy trials of collaborative care [100]. CHOICE was not designed to maximize reach of the intervention unlike many pragmatic trials [128-131]. At the same time, our analyses show that the 304 enrolled patients were similar in age and gender to the 2074 who declined or were never reached but had higher mean AUDIT-C scores indicative of more severe unhealthy alcohol use [132]. Given the positive association between severity of unhealthy alcohol use and readiness to change [133], we suspect recruited patients also had greater readiness to change than those who were not recruited. Despite efforts to oversample women, the CHOICE trial did not enroll adequate numbers of women to generalize trial findings to women.

Two prior approaches to chronic care management of AUDs in primary care, tested in recent randomized controlled trials, had markedly differing outcomes from each other: one showing a benefit of chronic care management and the other finding no benefit $[6,7]$. The two trials both blended pragmatic elements (intended to increase generalizability) with explanatory elements (intended to improve internal validity) but the samples, interventions, and comparisons in those studies differed in important ways from the CHOICE trial. A trial in the VA conducted by Oslin et al. [6] recruited primary care patients who met criteria for DSM-IV alcohol dependence irrespective of their readiness to change (excluding patients with other substance use and psychotic disorders). In contrast, the AHEAD trial by Saitz and colleagues included patients with DSM-IV AUD or other substance use disorders recruited outside primary care without exclusions, and many were seeking treatment. The median readiness to change was 10 (on a scale of 1-10) [7]. CHOICE, in contrast, recruited primary care patients with frequent heavy drinking, irrespective of comorbidity or symptoms of AUDs, and although most patients met criteria for AUDs, the median readiness to change was 5 . The intervention in the Oslin trial was delivered by behavioral health specialists (nurse or psychologist) [6], and the intervention in AHEAD was delivered by an interdisciplinary team (nurse, internist, social worker and psychiatrist) [7], while the CHOICE intervention was delivered by non-specialist nurses, supported weekly by an interdisciplinary team. The comparators of the three studies also differed; the Oslin study compared the intervention to referral to treatment [6], whereas AHEAD compared the intervention to referral to specialty addictions treatment and augmented primary care [7]. In contrast, the comparator in the CHOICE trial was usual primary care within a health care system that provided access to the full continuum of addiction specialty care. When the CHOICE trial results are available, thorough examination of the differences in the three studies may help identify promising elements of patient-centered care management of AUDs.

\section{Conclusion}

The CHOICE trial tested a novel intervention of 12 months of patient-centered care-offering repeated brief interventions using MI skills and shared decisionmaking-to engage patients at high risk for AUDs in alcohol-related care irrespective of their recognition of symptoms due to drinking, the presence or severity of AUDs, and/or readiness to change. Results of recruitment reported here suggest that the trial enrolled patients with the full spectrum of AUDs, of varying severity and readiness to change. Future reports will present findings regarding engagement with the intervention and main outcomes: reduced heavy drinking and drinking below recommended limits without symptoms.

\section{Additional file}

Additional file 1. Documentation regarding study procedures including recruitment materials (A), fictional example of initial CHOICE progress note template (B), fictional CHOICE patient roster (C), and differences between enrolled and non-enrolled samples.

\begin{abstract}
Abbreviations
AA: Alcoholics Anonymous; AUD: alcohol use disorder; AUDIT: Alcohol Use Disorder Identification Test; CDT: carbohydrate-deficient transferring; CHOICE: Choosing Healthier Drinking Options in primary CarE study; COMBINE: The Combined Pharmacotherapies and Behavioral Interventions study; DSM: Diagnostic and Statistical Manual of Mental Disorders; DUD: non-alcohol, non-tobacco drug use disorders; EHR: electronic health record; FDA: Food and Drug Administration; GAD-7: 7-Item Generalized Anxiety Disorder screen; GGT: gamma glutamyl transferase; MCV: mean corpuscular volume; MI: motivational interviewing; MINI: Mini International Neuropsychiatric Interview; NIAAA: National Institute on Alcohol Abuse and Alcoholism; PHQ-9: 9-item Patient Health Questionnaire; PTSD: Post-traumatic stress disorder; SF-12: 12item Short Form; SIP: Short Inventory of Problems; TLFB: time-line follow-back; VA: Veterans Affairs.
\end{abstract}

\section{Authors' contributions}

The following co-authors contributed to design of the CHOICE trial: KAB, EJL, JOM, AJS ECW, EH, and DRK. The following co-authors contributed to implementation, delivery, and innovation regarding the intervention: $K A B, E J L, S J R$, CEA, JOM, AJS, RMC, DMG. The following co-authors contributed to integrity of the data and analyses: LJC, JFB, AKL, JER, RMT, GL. All co-authors contributed to the design and editing of this manuscript.

\section{Author details}

${ }^{1}$ Kaiser Permanente Washington Health Research Institute, 1730 Minor Ave, Suite 1600, Seattle, WA 98101-1466, USA. ${ }^{2}$ Center of Excellence in Substance Abuse Treatment and Education (CESATE), Veterans Affairs (VA) Puget Sound Health Care System, Seattle, WA, USA. ${ }^{3}$ Health Services Research and Development (HSR\&D) Seattle Center of Innovation for Veteran-Centered and ValueDriven Care, Seattle, WA, USA. ${ }^{4}$ Department of Health Services, University 
of Washington, Seattle, WA, USA. ${ }^{5}$ Department of Medicine, University of Washington, Seattle, WA, USA. ${ }^{6}$ Division of Health Services Management and Policy, College of Public Health, The Ohio State University, Columbus, $\mathrm{OH}$, USA. ${ }^{7}$ Center for Innovation in Pediatric Practice, Nationwide Children's Hospital, Columbus, OH, USA. ${ }^{8}$ Department of Psychiatry and Behavioral Sciences, University of Washington, Seattle, WA, USA. ${ }^{9}$ General Medicine Service, Veterans Affairs (VA) Puget Sound Health Care System, Seattle, WA, USA.

\section{Competing interests}

The authors declare that they have no competing interest.

\section{Availability of data and materials}

The datasets generated during the current study are not publicly available due to privacy restrictions for veteran participants, but after planned papers are completed and published a de-identified dataset will be available from the corresponding author for reasonable requests.

\section{Ethics approval and consent to participate}

This study was approved to conduct an intervention and collect data from human participants by both the Group Health Research Institute and the Veteran's Affairs IRB committees.

\section{Funding}

This work was supported by National Institute of Alcohol Abuse and Alcoholism (NIAAA) AA018702; Health Services Research \& Development (HSR\&D) Center of Innovation for Veteran-Centered Value-Driven Care (COIN) and the General Internal Medicine Service at Veterans Affairs (VA) Puget Sound Health Care System, Seattle, WA and VA Puget Sound Center of Excellence for Substance Abuse Treatment \& Education, the Group Health Behavioral Health Service. Dr. Bradley is supported by a mid-career mentoring award from the National Institute on Alcohol Abuse and Alcoholism (K24-AA022128). Dr. Williams is supported by a Career Development Award from VA Health Services Research \& Development (CDA 12-276).

\section{Publisher's Note}

Springer Nature remains neutral with regard to jurisdictional claims in published maps and institutional affiliations.

Received: 12 October 2016 Accepted: 28 April 2017 Published online: 17 May 2017

\section{References}

1. Grant BF, Goldstein RB, Saha TD, Chou SP, Jung J, Zhang H, Pickering RP, Ruan WJ, Smith SM, Huang B, Hasin DS. Epidemiology of DSM-5 alcohol use disorder: results from the National Epidemiologic Survey on alcohol and related conditions III. JAMA Psychiatry. 2015;72:757-66.

2. Substance Abuse and Mental Health Services Administration: Results from the 2013 National Survey on Drug Use and Health: Summary of National Findings. In: NSDUH Series H-48, HHS Publication No. (SMA) 14-4863. Rockville, MD: Substance Abuse and Mental Health Services Administration; 2014.

3. Institute of Medicine. Broadening the base of treatment for alcohol problems: a report of the committee for the study of treatment and rehabilitation for alcoholism. Washington: National Academy Press; 1990.

4. Institute of Medicine. Improving the quality of health care for mental and substance-use conditions: quality Chasm series. Washington: National Academies Press; 2006.

5. Saitz R, Larson MJ, Labelle C, Richardson J, Samet JH. The case for chronic disease management for addiction. J Addict Med. 2008;2:55-65.

6. Oslin DW, Lynch KG, Maisto SA, Lantinga L, McKay JR, Possemato $\mathrm{K}$, Ingram E, Wierzbicki M. A randomized clinical trial of alcohol care management delivered in Department of Veterans Affairs primary care clinics versus specialty addiction treatment. J Gen Intern Med. 2014;29:162-8.
7. Saitz R, Cheng DM, Winter M, Kim TW, Meli SM, Allensworth-Davies D, Lloyd-Travaglini CA, Samet JH. Chronic care management for dependence on alcohol and other drugs: the AHEAD randomized trial. JAMA. 2013;310:1156-67.

8. Barry CL, Epstein AJ, Fiellin DA, Fraenkel L, Busch SH. Estimating demand for primary care-based treatment for substance and alcohol use disorders. Addiction. 2016;111:1376-84.

9. Upshur C, Weinreb L, Bharel M, Reed G, Frisard C. A randomized control trial of a chronic care intervention for homeless women with alcohol use problems. J Subst Abuse Treat. 2015;51:19-29.

10. ParkTW, Cheng DM, Samet JH, Winter MR, Saitz R. Chronic care management for substance dependence in primary care among patients with co-occurring disorders. Psychiatr Serv. 2015;66:72-9.

11. Barry MJ, Edgman-Levitan S. Shared decision making — pinnacle of patient-centered care. N Engl J Med. 2012;366:780-1.

12. Kristenson $\mathrm{H}$, Ohlin $\mathrm{H}$, Hulten-Nosslin M, Trell E, Hood B. Identification and intervention of heavy drinking in middle-aged men: results and follow-up of 24-60 months of long-term study with randomized controls. Alcohol Clin Exp Res. 1983;7:203-9.

13. Kristenson $\mathrm{H}$, Osterling A, Nilsson JA, Lindgarde F. Prevention of alcoholrelated deaths in middle-aged heavy drinkers. Alcohol Clin Exp Res. 2002;26:478-84.

14. Willenbring ML, Olson DH. A randomized trial of integrated outpatient treatment for medically ill alcoholic men. Arch Intern Med. 1999;159:1946-52.

15. Willenbring ML, Olson DH, Bielinski J. Integrated outpatients treatment for medically ill alcoholic men: results from a quasi-experimental study. J Stud Alcohol. 1995;56:337-43.

16. Brown RL, Dimond AR, Hulisz D, Saunders LA, Bobula JA. Pharmacoepidemiology of potential alcohol-prescription drug interactions among primary care patients with alcohol-use disorders. J Am Pharm Assoc. 2003;2007(47):135-9.

17. Lieber CS, Weiss DG, Groszmann R, Paronetto F, Schenker S. I. Veterans Affairs Cooperative Study of polyenylphosphatidylcholine in alcoholic liver disease: effects on drinking behavior by nurse/physician teams. Alcohol Clin Exp Res. 2003;27:1757-64.

18. Fleming MF, Barry KL, Manwell LB, Johnson K, London R. Brief physician advice for problem alcohol drinkers: a randomized controlled trial in community-based primary care practices. JAMA. 1997;277:1039-45.

19. Fleming MF, Mundt MP, French MT, Manwell LB, Stauffacher EA, Barry KL. Brief physician advice for problem drinkers: long-term efficacy and benefit-cost analysis. Alcohol Clin Exp Res. 2002;26:36-43.

20. Fleming MF, Mundt MP, French MT, Manwell LB, Stauffacher EA, Barry $\mathrm{KL}$. Benefit-cost analysis of brief physician advice with problem drinkers in primary care settings. Med Care. 2000;38:7-18.

21. Anton RF, O'Malley SS, Ciraulo DA, Cisler RA, Couper D, Donovan DM, Gastfriend DR, Hosking JD, Johnson BA, LoCastro JS, et al. Combined pharmacotherapies and behavioral interventions for alcohol dependence: the COMBINE study: a randomized controlled trial. JAMA. 2006;295:2003-17.

22. Nordback I, Pelli H, Lappalainen-Lehto R, Jarvinen S, Raty S, Sand J. The recurrence of acute alcohol-associated pancreatitis can be reduced: a randomized controlled trial. Gastroenterology. 2009;136:848-55.

23. Jonas D, Amick H, Feltner C, Bobashev G, Thomas K, Wines R, Kim M, Shanahan E, Gass C, Rowe C, Garbutt J. Pharmacotherapy for adults with alcohol-use disorders in outpatient settings: a systematic review and meta-analysis. JAMA. 2014;311:1889-900.

24. Curry SJ, Grossman DC, Whitlock EP, Cantu A. Behavioral counseling research and evidence-based practice recommendations: U.S. Preventive Services Task Force perspectives. Ann Intern Med. 2014;160:407-13.

25. Krist AH, Baumann LJ, Holtrop JS, Wasserman MR, Stange KC, Woo M. Evaluating feasible and referable behavioral counseling interventions. Am J Prev Med. 2015;49:S138-49.

26. Wagner EH, Austin BT, Von Korff M. Organizing care for patients with chronic illness. Milbank Q. 1996;74:511-44.

27. Von Korff M, Gruman J, Schaefer J, Curry SJ, Wagner EH. Collaborative management of chronic illness. Ann Intern Med. 1997;127:1097-102.

28. Coleman K, Austin BT, Brach C, Wagner EH. Evidence on the chronic care model in the new millennium. Health Aff (Millwood). 2009;28:75-85. 
29. Fortney JC, Pyne JM, Kimbrell TA, Hudson TJ, Robinson DE, Schneider R, Moore WM, Custer PJ, Grubbs KM, Schnurr PP. Telemedicine-based collaborative care for posttraumatic stress disorder: a randomized clinical trial. JAMA Psychiatry. 2015;72:58-67.

30. Fortney JC, Pyne JM, Mouden SB, Mittal D, Hudson TJ, Schroeder GW, Williams DK, Bynum CA, Mattox R, Rost KM. Practice-based versus telemedicine-based collaborative care for depression in rural federally qualified health centers: a pragmatic randomized comparative effectiveness trial. Am J Psychiatry. 2013;170:414-25.

31. Pyne JM, Fortney JC, Mouden S, Lu L, Hudson TJ, Mittal D. Cost-effectiveness of on-site versus off-site collaborative care for depression in rural FQHCs. Psychiatr Serv. 2015;66:491-9.

32. Fortney JC, Unutzer J, Wrenn G, Pyne JM, Smith GR, Schoenbaum M, Harbin HT. A tipping point for measurement-based care. Psychiatr Serv. 2017;68(2):179-88. doi:10.1176/appi.ps.201500439.

33. Katon W, Robinson P, Von Korff M, Lin E, Bush T, Ludman E, Simon G, Walker E. A multifaceted intervention to improve treatment of depression in primary care. Arch Gen Psychiatry. 1996;53:924-32.

34. Katon W, Von Korff M, Lin E, Simon G, Walker E, Unutzer J, Bush T, Russo J, Ludman E. Stepped collaborative care for primary care patients with persistent symptoms of depression: a randomized trial. Arch Gen Psychiatry. 1999;56:1109-15.

35. Katon W, Rutter C, Ludman EJ, Von Korff M, Lin E, Simon G, Bush T, Walker $\mathrm{E}$, Unutzer J. A randomized trial of relapse prevention of depression in primary care. Arch Gen Psychiatry. 2001;58:241-7.

36. Katon WJ, Von Korff M, Lin EH, Simon G, Ludman E, Russo J, Ciechanowski P, Walker E, Bush T. The Pathways Study: a randomized trial of collaborative care in patients with diabetes and depression. Arch Gen Psychiatry. 2004;61:1042-9.

37. Simon GE, Ludman EJ, Unutzer J, Bauer MS, Operskalski B, Rutter C. Randomized trial of a population-based care program for people with bipolar disorder. Psychol Med. 2005;35:13-24.

38. Katon W, Russo J, Reed SD, Croicu CA, Ludman E, LaRocco A, Melville $J \mathrm{~L}$. A randomized trial of collaborative depression care in obstetrics and gynecology clinics: socioeconomic disadvantage and treatment response. Am J Psychiatry. 2015;172:32-40.

39. Richardson LP, Ludman E, McCauley E, Lindenbaum J, Larison C, Zhou C, Clarke G, Brent D, Katon W. Collaborative care for adolescents with depression in primary care: a randomized clinical trial. JAMA. 2014:312:809-16.

40. Simon GE, Ludman EJ, Bauer MS, Unutzer J, Operskalski B. Long-term effectiveness and cost of a systematic care program for bipolar disorder. Arch Gen Psychiatry. 2006;63:500-8.

41. Katon W, Lin EH, Von Korff M, Ciechanowski P, Ludman E, Young B, Rutter C, Oliver M, McGregor M. Integrating depression and chronic disease care among patients with diabetes and/or coronary heart disease: the design of the TEAMcare study. Contemp Clin Trials. 2010;31:312-22.

42. Ludman E, Katon W, Bush T, Rutter C, Lin E, Simon G, Von Korff M, Walker E. Behavioural factors associated with symptom outcomes in a primary care-based depression prevention intervention trial. Psychol Med. 2003;33:1061-70.

43. Ludman E, Von Korff M, Katon W, Lin E, Simon G, Walker E, Unutzer J Bush T, Wahab S. The design, implementation, and acceptance of a primary care-based intervention to prevent depression relapse. Int J Psychiatry Med. 2000;30:229-45.

44. LeBlanc A, Herrin J, Williams MD, Inselman JW, Branda ME, Shah ND, Heim EM, Dick SR, Linzer M, Boehm DH, et al. Shared decision making for antidepressants in primary care: a cluster randomized trial. JAMA Intern Med. 2015;175:1761-70.

45. Tamhane S, Rodriguez-Gutierrez R, Hargraves I, Montori VM. Shared decision-making in diabetes care. Curr Diab Rep. 2015;15:112.

46. Stiggelbout AM, Van der Weijden T, De Wit MP, Frosch D, Legare F, Montori VM, Trevena L, Elwyn G. Shared decision making: really putting patients at the centre of healthcare. BMJ. 2012;344:e256.

47. Eddy DM. Clinical decision making: from theory to practice. Anatomy of a decision. JAMA. 1990;263:441-3.

48. Elwyn G, Frosch D, Volandes AE, Edwards A, Montori VM. Investing in deliberation: a definition and classification of decision support interventions for people facing difficult health decisions. Med Decis Mak. 2010;30:701-11.
49. Miller WR. Rediscovering fire: small interventions, large effects. Psychol Addict Behav. 2000;14:6-18.

50. Miller WR, Walters ST, Bennett ME. How effective is alcoholism treatment in the United States? J Stud Alcohol. 2001;62:211-20.

51. Miller WR, Wilbourne PL. Mesa Grande: a methodological analysis of clinical trials of treatments for alcohol use disorders. Addiction. 2002;97:265-77.

52. Joosten EA, de Jong CA, de Weert-van Oene GH, Sensky T, van der Staak CP. Shared decision-making reduces drug use and psychiatric severity in substance-dependent patients. Psychother Psychosom. 2009:78:245-53.

53. Joosten EA, De Jong CA, de Weert-van Oene GH, Sensky T, van der Staak CP. Shared decision-making: increases autonomy in substancedependent patients. Subst Use Misuse. 2011;46:1037-8.

54. Elwyn G, Dehlendorf C, Epstein RM, Marrin K, White J, Frosch DL. Shared decision making and motivational interviewing: achieving patientcentered care across the spectrum of health care problems. Ann Fam Med. 2014;12:270-5.

55. Elwyn G, Frosch D, Thomson R, Joseph-Williams N, Lloyd A, Kinnersley P, Cording E, Tomson D, Dodd C, Rollnick S, et al. Shared decision making: a model for clinical practice. J Gen Intern Med. 2012;27:1361-7.

56. Chafetz ME. Research in the alcohol clinic and around-the-clock psychiatric service of the Massachusetts General Hospital. Am J Psychiatry. 1968:124:1674-9.

57. Chafetz ME, Blane HT, Abram HS, Golner J, Lacy E, Mc CW, Clark E, Meyers W. Establishing treatment relations with alcoholics. J Nerv Ment Dis. 1962;134:395-409.

58. Chafetz ME, Blane HT, Abram HS, Clark E, Golner JH, Hastie EL, McCourt WF. Establishing treatment relations with alcoholics: a supplementary report. J Nerv Ment Dis. 1964;138:390-3.

59. Brown RL, Saunders LA, Bobula JA, Mundt MP, Koch PE. Randomizedcontrolled trial of a telephone and mail intervention for alcohol use disorders: three-month drinking outcomes. Alcohol Clin Exp Res. 2007;31:1372-9.

60. Helzer JE, Rose GL, Badger GJ, Searles JS, Thomas CS, Lindberg SA, Guth S. Using interactive voice response to enhance brief alcohol intervention in primary care settings. J Stud Alcohol Drugs. 2008;69:251-8.

61. Smedslund G, Berg RC, Hammerstrom KT, Steiro A, Leiknes KA, Dahl HM Karlsen K. Motivational interviewing for substance abuse. Cochrane Database Syst Rev. 2011;11(5):CD008063. doi:10.1002/14651858. CD008063.pub2.

62. Conigrave KM, Degenhardt LJ, Whitfield JB, Saunders JB, Helander A, Tabakoff B. CDT, GGT, and AST as markers of alcohol use: the WHO/ ISBRA collaborative project. Alcohol Clin Exp Res. 2002;26:332-9.

63. Yersin B, Nicolet JF, Dercrey H, Burnier M, van Melle G, Pecoud A. Screening for excessive alcohol drinking. Comparative value of carbohydrate-deficient transferrin, gamma-glutamyltransferase, and mean corpuscular volume. Arch Intern Med. 1995;155:1907-11.

64. Fleming $M$, Brown $R$, Brown D. The efficacy of a brief alcohol intervention combined with \%CDT feedback in patients being treated for type 2 diabetes and/or hypertension. J Stud Alcohol. 2004;65:631-7.

65. National Institute on Alcohol Abuse and Alcoholism. Helping patients who drink too much: a clinician's guide (updated 2005 edition). Washington: National Institutes of Health, U.S. Department of Health and Human Services; 2005.

66. Saitz R. Medications for alcohol use disorders. JAMA. 2014;312:1349.

67. Ernst DB, Pettinati HM, Weiss RD, Donovan DM, Longabaugh R. An intervention for treating alcohol dependence: relating elements of Medical Management to patient outcomes with implications for primary care. Ann Fam Med. 2008;6:435-40.

68. Coulehan JL, Zettler-Segal M, Block M, MCClelland M, Schulberg HC Recognition of alcoholism and substance abuse in primary care patients. Arch Intern Med. 1987;147:349-52.

69. Rehm J, Allamani A, Della Vedova R, Elekes Z, Jakubczyk A, Landsmane I, Manthey J, Moreno-Espana J, Pieper L, Probst C, et al. General practitioners recognizing alcohol dependence: a large cross-sectional study in 6 European countries. Ann Fam Med. 2015;13:28-32.

70. Saha TD, Chou SP, Grant BF. Toward an alcohol use disorder continuum using item response theory: results from the National Epidemiologic Survey on Alcohol and Related Conditions. Psychol Med. 2006:36:931-41. 
71. Bradley KA, Kivlahan DR, Zhou XH, Sporleder JL, Epler AJ, McCormick KA, Merrill JO, McDonell MB, Finn SD. Using alcohol screening results and treatment history to assess the severity of at-risk drinking in Veterans Affairs primary care patients. Alcohol Clin Exp Res. 2004;28:448-55.

72. Bradley KA, DeBenedetti AF, Volk RJ, Williams EC, Frank D, Kivlahan DR. AUDIT-C as a brief screen for alcohol misuse in primary care. Alcohol Clin Exp Res. 2007;31:1208-17.

73. Kypri K, Langley JD, Saunders JB, Cashell-Smith ML. Assessment may conceal therapeutic benefit: findings from a randomized controlled trial for hazardous drinking. Addiction. 2007:102:62-70.

74. McCambridge J, Kypri K. Can simply answering research questions change behaviour? Systematic review and meta analyses of brief alcohol intervention trials. PLoS ONE. 2011;6:e23748.

75. Moos RH. Context and mechanisms of reactivity to assessment and treatment. Addiction. 2008;103:249-50.

76. Orford J, Hodgson R, Copello A, John B, Smith M, Black R, Fryer K, Handforth L, Alwyn T, Kerr C, et al. The clients' perspective on change during treatment for an alcohol problem: qualitative analysis of follow-up interviews in the UK Alcohol Treatment Trial. Addiction. 2006;101:60-8.

77. Orford J, Kerr C, Copello A, Hodgson R, Alwyn T, Black R, Smith M, Thistlethwaite G, Westwood A, Slegg G. Why people enter treatment for alcohol problems: findings from UK Alcohol Treatment Trial pretreatment. J Subst Use. 2006;11:161-76.

78. Mercer A, Caporaso A, Cantor D, Townsend R. How much gets you how much? Monetary incentives and response rates in household surveys. Public Opin Q. 2015;79:105-29.

79. Singer E, Van Hoewyk J, Maher MP. Experiments with incentives in telephone surveys. Public Opin Q. 2000;64:171-88.

80. Leeuw ED, Callegaro M, Hox J, Korendijk E, Lensvelt-Mulders G. The influence of advance letters on response in telephone surveys: a metaanalysis. Public Opin Q. 2007;71:413-43.

81. Borson S, Scanlan J, Brush M, Vitaliano P, Dokmak A. The mini-cog: a cognitive'vital signs' measure for dementia screening in multi-lingual elderly. Int J Geriatr Psychiatry. 2000;15:1021-7.

82. Borson S, Scanlan JM, Chen P, Ganguli M. The Mini-Cog as a screen for dementia: validation in a population-based sample. J Am Geriatr Soc. 2003;51:1451-4

83. Borson S, Scanlan JM, Watanabe J, Tu SP, Lessig M. Simplifying detection of cognitive impairment: comparison of the Mini-Cog and MiniMental State Examination in a multiethnic sample. J Am Geriatr Soc. 2005;53:871-4.

84. Brodaty H, Low LF, Gibson L, Burns K. What is the best dementia screening instrument for general practitioners to use? Am J Geriatr Psychiatry. 2006;14:391-400.

85. Milne A, Culverwell A, Guss R, Tuppen J, Whelton R. Screening for dementia in primary care: a review of the use, efficacy and quality of measures. Int Psychogeriatr. 2008;20:911-26.

86. Babor TF, de la Fuente JR, Saunders J, Grant M. AUDIT: Alcohol Use Disorders Identification Test: guidelines for use in primary health care. Geneva: World Health Organization; 1989.

87. Kroenke K, Spitzer RL, Williams JB. The PHQ-9: validity of a brief depression severity measure. J Gen Intern Med. 2001;16:606-13.

88. Sheehan DV, Lecrubier Y, Sheehan KH, Amorim P, Janavs J, Weiller E, Herqueta T, Baker R, Dunbar GC. The Mini-International Neuropsychiatric Interview (M.I.N.I.): the development and validation of a structured diagnostic psychiatric interview for DSM-IV and ICD-10. J Clin Psychiatry. 1998;59(Suppl 20):22-33 (quiz 34-57)

89. Blanchard E, Jones-Alexander J, Buckley T, Forneris C. Psychometric properties of the PTSD checklist (PCL). Behav Res Ther. 1996;34:669-73.

90. Sobell LC, Brown J, Leo GI, Sobell MB. The reliability of the alcohol timeline followback when administered by telephone and by computer. Drug Alcohol Depend. 1996;42:49-54.

91. Miller WR, Tonigan JS, Longabaugh R. The drinker inventory of consequences (DrlnC): an instrument for assessing adverse consequences of alcohol abuse. Bethesda: U.S. Department of Health and Human Services; 1995.

92. Forcehimes AA, Tonigan JS, Miller WR, Kenna GA, Baer JS. Psychometrics of the Drinker Inventory of Consequences (DrlnC). Addict Behav. 2007;32:1699-704.
93. Bradley KA, Williams EC, Achtmeyer CE, Volpp B, Collins BJ, Kivlahan DR. Implementation of evidence-based alcohol screening in the Veterans Health Administration. Am J Manag Care. 2006;12:597-606.

94. Lapham GT, Achtmeyer CE, Williams EC, Hawkins EJ, Kivlahan DR, Bradley KA. Increased documented brief alcohol interventions with a performance measure and electronic decision support. Med Care. 2012;50:179-87.

95. Chavez L, Williams EC, Lapham GT, Rubinsky AD, Kivlahan DR, Bradley KA: Changes in Patient-reported alcohol-related advice following Veterans Health Administration implementation of brief alcohol interventions. J Stud Alcohol Drugs. 2016;77(3):500-8

96. Post EP, Metzger M, Dumas P, Lehmann L. Integrating mental health into primary care within the Veterans Health Administration. Fam Syst Health. 2010;28:83-90.

97. Nelson KM, Helfrich C, Sun H, Hebert PL, Liu CF, Dolan E, Taylor L, Wong E, Maynard C, Hernandez SE, et al. Implementation of the patient-centered medical home in the Veterans Health Administration: associations with patient satisfaction, quality of care, staff burnout, and hospital and emergency department use. JAMA Intern Med. 2014;174:1350-8.

98. Gastfriend DR, Garbutt JC, Pettinati HM, Forman RF. Reduction in heavy drinking as a treatment outcome in alcohol dependence. J Subst Abuse Treat. 2007:33:71-80.

99. Cisler RA, Zweben A. Development of a composite measure for assessing alcohol treatment outcome: operationalization and validation. Alcohol Clin Exp Res. 1999;23:263-71.

100. Katon WJ, Lin EH, Von Korff M, Ciechanowski P, Ludman EJ, Young B, Peterson D, Rutter CM, McGregor M, McCulloch D. Collaborative care for patients with depression and chronic illnesses. N Engl I Med. 2010:363:2611-20.

101. Bekelman DB, Plomondon ME, Carey EP, Sullivan MD, Nelson KM, Hattler B, McBryde CF, Lehmann KG, Gianola K, Heidenreich PA, Rumsfeld JS. Primary Results of the Patient-Centered Disease Management (PCDM) for Heart Failure Study: a randomized clinical trial. JAMA Intern Med. 2015;175:725-32.

102. Curry SJ, McBride C, Grothaus LC, Louie D. A randomized trial of selfhelp materials, personalized feedback, and telephone counseling with nonvolunteer smokers. J Consult Clin Psychol. 1995;63:1005-14.

103. Simon GE, Ludman EJ, Operskalski BH. Randomized trial of a telephone care management program for outpatients starting antidepressant treatment. Psychiatr Serv. 2006:57:1441-5.

104. Simon GE, Ludman EJ, Tutty S, Operskalski B, Von Korff M. Telephone psychotherapy and telephone care management for primary care patients starting antidepressant treatment: a randomized controlled trial. JAMA. 2004:292:935-42.

105. Ludman EJ, Simon GE, Grothaus LC, Luce C, Markley DK, Schaefer J. A pilot study of telephone care management and structured disease self-management groups for chronic depression. Psychiatr Serv. 2007:58:1065-72.

106. Ludman EJ, Simon GE, Tutty S, Von Korff M. A randomized trial of telephone psychotherapy and pharmacotherapy for depression: continuation and durability of effects. J Consult Clin Psychol. 2007;75:257-66.

107. Pettinati HM, Weiss RD, Miller WR, Donovan D, Ernst DB, Rounsaville BJ: Medical management treatment manual: a clinical research guide for medically trained clinicians providing pharmacotherapy as part of the treatment for alcohol dependence. DHHS Publication No. (NIH) 04-5289 edn. Bethesda: NIAAA; 2004.

108. National Institute on Alcohol Abuse and Alcoholism. Rethinking drinking: alcohol and your health. Bethesda: National Institutes of Health, U.S. Department of Health and Human Services: 2009.

109. Grote NK, Zuckoff A, Swartz H, Bledsoe SE, Geibel S. Engaging women who are depressed and economically disadvantaged in mental health treatment. Soc Work. 2007;52:295-308.

110. West SG, Duan N, Pequegnat W, Gaist P, Des Jarlais DC, Holtgrave D, Szapocznik J, Fishbein M, Rapkin B, Clatts M, Mullen PD. Alternatives to the randomized controlled trial. Am J Public Health. 2008;98:1359-66.

111. Zhou XH, Li SM. ITT analysis of randomized encouragement design studies with missing data. Stat Med. 2006;25:2737-61.

112. Taylor L, Zhou XH. Multiple imputation methods for treatment noncompliance and nonresponse in randomized clinical trials. Biometrics. 2009;65:88-95. 
113. Taylor L, Zhou XH. Methods for clustered encouragement design studies with noncompliance and missing data. Biostatistics. 2011;12:313-26.

114. Bradley KA, Rubinsky AD, Lapham GT, Berger D, Bryson C, Achtmeyer C, Hawkins EJ, Chavez LJ, Williams EC, Kivlahan DR. Predictive validity of clinical AUDIT-C alcohol screening scores and changes in scores for three objective alcohol-related outcomes in a Veterans Affairs population. Addiction. 2016;111:1975-84.

115. Kroenke K, Spitzer RL, Williams JB, Monahan PO, Lowe B. Anxiety disorders in primary care: prevalence, impairment, comorbidity, and detection. Ann Intern Med. 2007;146:317-25.

116. Murphy CM, Stojek MK, Few LR, Rothbaum AO, Mackillop J. Craving as an alcohol use disorder symptom in DSM-5: an empirical examination in a treatment-seeking sample. Exp Clin Psychopharmacol. 2014;22:43-9.

117. Aertgeerts B, Buntinx F, Ansoms S, Fevery J. Screening properties of questionnaires and laboratory tests for the detection of alcohol abuse or dependence in a general practice population. Br J Gen Pract. 2001:51:206-17.

118. Anton RF, Lieber C, Tabakoff B. Carbohydrate-deficient transferrin and gamma-glutamyltransferase for the detection and monitoring of alcohol use: results from a multisite study. Alcohol Clin Exp Res. 2002:26:1215-22.

119. Miller WR. Sacred cows and greener pastures: reflections from 40 years in addiction research. Alcohol Treat Q. 2016;34:92-115.

120. AUDIT: The Alcohol Use Disorders Identification Test: guidelines for use in primary care, 2nd edn. http://www.dass.stir.ac.uk/DRUGS/pdf/audit. pdf.

121. Kessler RS, Purcell EP, Glasgow RE, Klesges LM, Benkeser RM, Peek CJ. What does it mean to "employ" the RE-AIM model? Eval Health Prof. 2013;36:44-66.

122. Grossman DC, Elder RW. Aligning the work of two U.S. Task Forces on behavioral counseling recommendations. Am J Prev Med. 2015:49:S174-83.

123. Thorpe KE, Zwarenstein M, Oxman AD, Treweek S, Furberg CD, Altman DG, Tunis S, Bergel E, Harvey I, Magid DJ, Chalkidou K. A pragmaticexplanatory continuum indicator summary (PRECIS): a tool to help trial designers. CMAJ. 2009;180:E47-57.

124. Saha TD, Stinson FS, Grant BF. The role of alcohol consumption in future classifications of alcohol use disorders. Drug Alcohol Depend. 2007:89:82-92.

125. Jonas DE, Garbutt JC, Amick HR, Brown JM, Brownley KA, Council CL, Viera AJ, Wilkins TM, Schwartz CJ, Richmond EM, et al. Behavioral counseling after screening for alcohol misuse in primary care: a systematic review and meta-analysis for the U.S. Preventive Services Task Force. Ann Intern Med. 2012;157:645-54.

126. Keyes KM, Hatzenbuehler ML, McLaughlin KA, Link B, Olfson M, Grant BF, Hasin D. Stigma and treatment for alcohol disorders in the United States. Am J Epidemiol. 2010;172(12):1364-72. doi:10.1093/aje/kwq304

127. Orford J, Hodgson R, Copello A, Wilton S, Slegg G, Team UR. To what factors do clients attribute change? Content analysis of follow-up interviews with clients of the UK Alcohol Treatment Trial. J Subst Abuse Treat. 2009;36:49-58.
128. Glasgow RE, McKay HG, Piette JD, Reynolds KD. The RE-AIM framework for evaluating interventions: what can it tell us about approaches to chronic illness management? Patient Educ Couns. 2001;44:119-27.

129. Feldstein AC, Glasgow RE. A practical, robust implementation and sustainability model (PRISM) for integrating research findings into practice. Jt Comm J Qual Patient Saf. 2008;34:228-43.

130. Gaglio B, Shoup JA, Glasgow RE. The RE-AIM framework: a systematic review of use over time. Am J Public Health. 2013;103:e38-46.

131. Glasgow RE, Vogt TM, Boles SM. Evaluating the public health impact of health promotion interventions: the RE-AIM framework. Am J Public Health. 1999:89:1322-7.

132. Rubinsky AD, Dawson DA, Williams EC, Kivlahan DR, Bradley KA. AUDITC scores as a scaled marker of mean daily drinking, alcohol use disorder severity, and probability of alcohol dependence in a U.S. general population sample of drinkers. Alcohol Clin Exp Res. 2013;37:1380-90.

133. Williams EC, Kivlahan DR, Saitz R, Merrill JO, Achtmeyer CE, McCormick KA, Bradley KA. Readiness to change in primary care patients who screened positive for alcohol misuse. Ann Fam Med. 2006:4:213-20.

134. Ware J Jr, Kosinski M, Keller SD. A 12-Item Short-Form Health Survey: construction of scales and preliminary tests of reliability and validity. Med Care. 1996;34:220-33.

135. Jones D, Kazis L, Lee A, Rogers W, Skinner K, Cassar L, Wilson N, Hendricks A. Health status assessments using the Veterans SF-12 and SF-36: methods for evaluating otucomes in the Veterans Health Administration. J Ambul Care Manag. 2001;24:68-86.

136. Agrawal A, Heath AC, Lynskey MT. DSM-IV to DSM-5: the impact of proposed revisions on diagnosis of alcohol use disorders. Addiction. 2011;106:1935-43.

137. Hasin DS, O'Brien CP, Auriacombe M, Borges G, Bucholz K, Budney A, Compton WM, Crowley T, Ling W, Petry NM, et al. DSM-5 criteria for substance use disorders: recommendations and rationale. Am J Psychiatry. 2013;170:834-51.

138. Saitz R, Horton NJ, Sullivan LM, Moskowitz MA, Samet JH. Addressing alcohol problems in primary care: a cluster randomized, controlled trial of a systems intervention. The screening and intervention in primary care (SIP) study. Ann Intern Med. 2003;138:372-82.

139. Williams EC, Horton NJ, Samet JH, Saitz R. Do brief measures of readiness to change predict alcohol consumption and consequences in primary care patients with unhealthy alcohol use? Alcohol Clin Exp Res. 2007:31:428-35.

140. Longabaugh R, Wirtz PW, Zywiak WH, O'Malley SS. Network support as a prognostic indicator of drinking outcomes: the COMBINE Study. J Stud Alcohol Drugs. 2010;71:837-46.

141. Humphreys K, Kaskutas LA, Weisner C. The Alcoholics Anonymous Affiliation Scale: development, reliability, and norms for diverse treated and untreated populations. Alcohol Clin Exp Res. 1998;22:974-8.

\section{Submit your next manuscript to BioMed Central and we will help you at every step:}

- We accept pre-submission inquiries

- Our selector tool helps you to find the most relevant journal

- We provide round the clock customer support

- Convenient online submission

- Thorough peer review

- Inclusion in PubMed and all major indexing services

- Maximum visibility for your research

Submit your manuscript at www.biomedcentral.com/submit 